\title{
Informal Network Structure and Knowledge Sharing in Organizations: An Empirical Study of a Korean Paint Manufacturing Company
}

\author{
Woojin Yoon (D), Jaeyun Jeong and Kyoung Won Park*(D) \\ Department of Business Administration, Hanyang University, ERICA Campus, 55 Hanyangdaehak-ro, \\ Ansan-si 15588, Gyeonggi-do, Korea; wyoon@hanyang.ac.kr (W.Y.); dykjy@hanyang.ac.kr (J.J.) \\ * Correspondence: kwp@hanyang.ac.kr
}

Citation: Yoon, Woojin, Jaeyun Jeong, and Kyoung Won Park. 2021. Informal Network Structure and Knowledge Sharing in Organizations: An Empirical Study of a Korean Paint Manufacturing Company.

Administrative Sciences 11: 52.

https://doi.org/10.3390/

admsci11020052

Received: 21 April 2021

Accepted: 13 May 2021

Published: 20 May 2021

Publisher's Note: MDPI stays neutral with regard to jurisdictional claims in published maps and institutional affiliations.

Copyright: (c) 2021 by the authors. Licensee MDPI, Basel, Switzerland. This article is an open access article distributed under the terms and conditions of the Creative Commons Attribution (CC BY) license (https:/ / creativecommons.org/licenses/by/ $4.0 /)$.

\begin{abstract}
This study investigates the potentially different roles of informal social networks in promoting knowledge sharing. Specifically, it aims to examine the effects of the focal subgroup's between-subgroup network size and strength on knowledge sharing with other subgroups and the moderating effect of within-subgroup network strength on the relationship of between-subgroup network size to knowledge sharing. Two different online surveys were conducted to assess social networks and knowledge sharing at a paint manufacturing company located in Gyeonggi Province, South Korea. The final sample consisted of 536 employees in 58 teams. The team-level regression results showed that the focal subgroup's between-subgroup network strength has a significant effect on knowledge sharing with other subgroups, indicating that strong ties among subgroups are more advantageous to external knowledge sharing than weak ties. The results also demonstrated that the focal subgroup's within-subgroup network strength negatively moderates the effect of its betweensubgroup network size on knowledge sharing, indicating that higher levels of between-subgroup network size are positively related to external knowledge sharing when within-subgroup network strength is weak and negatively when within-subgroup network strength is strong. The study's findings suggest that strong ties among subgroups and weak ties among subgroup members are advantageous to external knowledge sharing.
\end{abstract}

Keywords: informal network; social capital; network size; network strength; knowledge sharing

\section{Introduction}

Knowledge sharing in an organization is an important factor to secure continuous competitive advantage (Almeida and Kogut 1999; Argote and Ingram 2000; Chung and Yoon 2020; Hansen 2002; Kogut and Zander 1992; Yoon et al. 2015). According to the knowledge-based view of firms, an organization as a social community possesses an efficient mechanism to create, transfer, and share knowledge across the organization (Argote and Fahrenkopf 2016; Grant 1996; Kogut and Zander 1996). Subgroups within the organization as members of the knowledge community exchange information with each other through formal and informal interactions, create knowledge, and benefit from sharing knowledge created by other subgroups (Tsai 2002). Aligned with this view, Almeida et al. (2002) demonstrated that the organization structure is an efficient mechanism for knowledge transfer and sharing.

A large body of literature to identify factors that facilitate knowledge sharing within an organization has evolved. First, one research stream has emphasized the relevance of knowledge or skill base among subunits for knowledge sharing (e.g., Farjoun 1998; Foss and Pedersen 2019; Markides and Williamson 1994). This approach implies that a company's headquarters would identify and coordinate its subunits' knowledge contents to facilitate knowledge sharing and create synergy. However, this premise has not received empirical support, probably because it failed to consider lateral relations among subunits. 
Second, another research stream has emphasized the organization's information processing capacity, by analyzing subunit relations within the organization (e.g., Galbraith 1973; Gupta and Govindarajan 2000). This approach seems to assume that the organization exists in a vacuum space and, therefore, the presence of multiple channels to process information would naturally lead to knowledge transfer in the organization. Even with the organization's crafting efforts, stickiness arising from the tacit nature of knowledge often makes knowledge transfer and sharing difficult to occur (Szulanski 1996). Furthermore, information as such is processed by subunit members who often interact with other members within and across subunits. Therefore, the organization's information processing capacity needs to be considered in a social context, in which information is processed.

Third, one recent research stream has emphasized the role of informal network structure in knowledge transfer and sharing (Cummings 2004; Hansen 1999; Gupta and Govindarajan 2000; Levin and Cross 2004; Paruchuri and Awate 2017; Tsai 2001; Tortoriello 2015). This research stream views information and knowledge as resources that flow through informal networks, based on social capital theory. Knowledge transfer and sharing occur due to social interactions in the networks. Knowledge acquisition and sharing are the direct benefits of social capital accumulated in the networks (Adler and Kwon 2002; Nahapiet and Ghoshal 1998). However, this research stream has focused on a particular set of informal networks without sufficient consideration of the possibility that multiple subsets of relations in the organization may have differential effects on knowledge transfer and sharing (Hansen et al. 2005). Consequently, the informal network structure's roles in knowledge transfer and sharing have not been fully addressed theoretically and empirically.

This study explores the potentially different effects of informal network structures on external knowledge sharing. Based on the knowledge-based view of the firm and social capital theory, it examines how between-subgroup network size and strength affect knowledge sharing among other subgroups. This study also examines how within-subgroup network strength moderates the relationship between the size of the between-subgroup network and knowledge sharing. It is hypothesized that the within-subgroup network strength negatively moderates the effect of between-subgroup network size on knowledge sharing among other subgroups.

The findings of this study are twofold. First, this study empirically showed that the between-subgroup network strength is positively and significantly associated with knowledge sharing among the other subgroups. Second, it also showed that withinsubgroup network strength negatively and significantly moderates the relationship of between-subgroup network size with external knowledge sharing.

Overall, these findings have important theoretical and practical implications for the literature on external knowledge sharing. First, this study emphasizes the role of network strength between subgroups in external knowledge sharing. To create knowledge flow among subgroups in organizations, managers should focus on enhancing the bonds between subgroups by providing opportunities to interact and creating environments in which subgroups collaborate. Second, this study also emphasizes the importance of two subsets of informal network structures in external knowledge sharing. Therefore, this study contributes to research by empirically demonstrating the heterogeneous roles of multiple subsets of informal networks in external knowledge sharing.

\section{Literature Review}

\subsection{Concept of Social Capital}

There is no widely accepted consensus regarding the definition and effects of social capital (Koka and Prescott 2002). This study conducts a literature review on the concept of social capital by Bourdieu (1986) and Coleman $(1988,1990)$, who conducted the first systematic research on social capital.

Bourdieu (1986) distinguished three forms of capital that an individual can possess. Economic capital is translated into currency (Chu and Yoon 2020a), cultural capital is translated into economic currency under specific circumstances, and social capital is a 
resource and opportunity that are obtained from persistent social networks composed of institutionalized social relations. Bourdieu defined social capital as the total sum of potential or actual benefits and opportunities that an individual or a group can gain from forms of capital owned by group members or social networks, or from the institutionalized relationship of closeness or mutual awareness, or persistent connectedness (1986, p. 21). According to Bourdieu's theory, social capital is an invisible network itself that persistently reproduces exclusive benefits for its members.

Coleman $(1988,1990)$ classified forms of capital into the material capital, human capital, and social capital. Material capital refers to actualized capital such as machinery and equipment. Human capital refers to individuals' knowledge, skills, abilities, or other competencies that can be typically attained through formal education and job training. Social capital refers to social relations or social structures that facilitate actions to achieve specific goals, that is, productive social networks. For Coleman, social capital exists within the relational structures among individuals or groups and has economic potential for productive purposes. Social capital takes various forms, such as systems of trust and obligations, networks disseminating information, norms accompanied by sanctioning systems, and centralized authority structures arising through transfers of control (Coleman 1988). In Coleman's theory, social capital is an aspect of social relations or social structure that enables individuals to perform specific actions jointly. It is a useful resource for people who are willing to form social groups or social communities because it reduces transaction costs and facilitates communication.

Bourdieu viewed social capital as a resource that reproduces exclusive privileges for actors located within social networks. In contrast, Coleman viewed it as those with public goods characteristics obtained through the formation of social relations. However, it is common for individual actors to provide differential benefits via social capital based on social relations. Social capital can be conceptualized as benefits that individual actors can obtain under their social network memberships.

When a company is considered an actor, its social capital can be treated as similar to that of individuals. However, the company's social capital can be divided into three levels at which social relations occur. First, social capital exists among individuals. It includes the relational structures expressed as the characteristics of social relationships among individual members of the company, and the common norms, trust, cooperation, identity, etc., revealed by the relational structures (e.g., Ferrin et al. 2006; Levin and Cross 2004). Second, social capital can exist among companies, appearing in formal and informal social relations among other companies (e.g., Beckman et al. 2004; Gulati 2007; Iftikhar and Ahola 2020; Shipilov 2006). Third, social capital exists between companies and society. It includes social awareness, legitimacy, or trust that the company obtains from a society where it is located or society in general (e.g., Audia et al. 2006; Provan and Kenis 2008; Owen-Smith and Powell 2004). In this regard, various efforts to fulfill corporate social responsibilities can be interpreted as investments in building social capital.

\subsection{Role of Social Capital in the Organization}

Various activities within the organization may occur without resorting to the official hierarchical structure (Galbraith 1973). Unofficial and potential relations among organizational members or subgroups often play important roles in communicating and coordinating their activities (Tsai 2002), an example of the direct benefits from social capital within an organization. The role of social capital can be understood in terms of information, control, and solidarity (Sandefur et al. 1999; Yoon and Hyun 2010). First, because individuals typically obtain information needed from their social contacts, individuals holding advantageous positions in networks can obtain such information faster than those in disadvantageous positions. Second, depending on the characteristics of social networks to which individuals belong, they can control their colleagues effectively with little effort. Third, individuals who share social capital can easily share goals, values, and norms (Chu and Yoon 2021), thereby developing a sense of solidarity. 
Various social interactions within the organization help members from other subgroups establish channels for information exchange, and these established channels provide easy access to the resources and knowledge that each subgroup possesses (Aral 2016; Gupta et al. 1999; Paruchuri and Awate 2017). Additionally, social interactions function to develop and share common interests to establish a new exchange or cooperative relations beyond the official organizational structure (Tsai and Ghoshal 1998). These social interactions can promote social capital formation, accelerating knowledge transfer among subgroups (Coleman 1990). Social capital that forms at various levels of the organization is embedded in social networks, and members of social networks share information and knowledge through persistent social interactions. Therefore, social capital functions as an important mechanism that accelerates the transfer, sharing, and spreading of knowledge within an organization.

Social capital also facilitates organizational members' sharing of organizational goals and culture (Nahapiet and Ghoshal 1998). Shared goals help members share a common understanding and approach to completing tasks and accomplishing desired goals. Shared culture helps members share norms of behavior to coordinate their relationships and activities, and becomes institutionalized in the network structure and sets a standard of appropriate behavior (Park et al. 2018). Thus, social capital can develop a sense of solidarity and provide effective control over the network structure members without incurring substantial costs. However, social capital can be negative because shared norms may develop into excessive norms of behavior to the members and eventually block exploration of new alternatives beyond the network structure (Inkpen and Tsang 2005).

\subsection{Network Structure and Knowledge Sharing}

A key characteristic of network structure is that actors in the network form repetitive and persistent exchange relationships (Albers et al. 2016; Kim and Yoon 2019; Podolny and Page 1998). In this regard, knowledge transfer and sharing are understood to occur from how actors in the network structure learn from each other (Argote and Ingram 2000; $\mathrm{Chu}$ and Yoon 2020b; Howard et al. 2016). Once the exchange relationship is established, a structural position in the network structure can be interpreted regarding resource possession (Nahapiet and Ghoshal 1998; Tortoriello 2015). Holding a structural position means being accessible to information and knowledge that flows through the network structure. An actor who does not hold a position is restricted to accessing the available resources. Burt (1992) enumerated three major benefits from information flows through a network structure. First, information flows provide information on who possesses, accesses, and uses valuable information. The network actors can effectively exploit the screening and distribution of information circulating in the network. Second, actors in the network can obtain information faster than actors not in the network. Third, information flows provide appropriate opportunities for actors in the network. In short, social networks per se function as information channels that reduce the time and resources required to obtain information.

Consistent with the literature, the majority of research has identified conditions in which informal networks promote or hinder knowledge sharing, but with a limited set of particular networks, such as within-subunit networks (Levin and Cross 2004), betweensubunit networks (Gupta and Govindarajan 2000), and outside networks of individual actors (Cummings 2004). The network structure that constitutes various actors comprises multiple subsets of relations in an organization (Hansen et al. 2005). Specific nodes in the network structure often serve as those in a subset of relations at different organization levels and function as contexts encompassing another subset of relations. For example, the organization has a network structure composed of its subunits, and each subunit simultaneously functions as a context encompassing another subset of relations among its members. Therefore, the presence of multiple subsets of relations should be considered to identify the conditions under which informal networks promote knowledge sharing. Otherwise, 
our understanding of how subsets of relations in an organization affect knowledge sharing would remain incomplete.

Specifically, we focus on two distinctive subunit networks, i.e., between-subunit networks and within-subunit networks, in organizations (Hansen et al. 2005). Betweensubunit networks form through each subunit's interrelationships with other subunits for their tasks. Within-subunit networks form when members of each subunit create their patterns of networks within the subunit. In our research context, the major difference between the two subunit networks is the level at which social capital is embedded. Betweensubunit networks manifest social capital existing at the organization's subunit, while within-subunit networks manifest social capital existing at the individual members of each subunit. We investigate how these two subunit networks interact with each other to promote external knowledge sharing.

\section{Hypotheses Development}

\subsection{Between-Subgroup Network Size}

The network's scope refers to how a focal subgroup's ties are prevalent beyond it (Burt 1992). As the scope of a focal subgroup network increases, the focal subgroup members would be better positioned to access more information and knowledge (Paruchuri and Awate 2017), thereby developing multiple perspectives and attaining such resources ( Reagans and McEvily 2003). Social interactions with other subgroup members who have multiple perspectives and experiences help the focal subgroup members build a common knowledge base and promote the basic skills and capabilities required to acquire and share new knowledge (Cohen and Levinthal 1990; Uzzi 1997). The common knowledge base in a dyadic relationship in which knowledge acquisition and transfer occur is an important condition for smooth knowledge flows (Reagans and McEvily 2003; Tortoriello 2015). Therefore, the larger scope of the network would allow the focal group members to learn the varied knowledge and experiences that subgroups possess. The common knowledge base increases the likelihood of knowledge transfer and sharing from other subgroups to the focal subgroup.

The larger scope of the network raises awareness about external knowledge (Austin 2003). The raised awareness would increase information on where the knowledge necessary for tasks exists, which would further empower the focal subgroup to acquire knowledge from other subgroups (Hansen et al. 2005).

Based on theoretical accounts of the common knowledge base and raised awareness about external knowledge, the first hypothesis is as follows:

Hypothesis 1. As the size of the between-subgroup network of a focal subgroup increases, the focal subgroup's knowledge sharing with other subgroups increases.

\subsection{Between-Subgroup Network Strength}

The tacit and sticky nature of knowledge makes internal knowledge transfer and sharing difficult, even within the organization (Szulanski 1996). The overall organizational socialization level is important in extracting the tacitness of knowledge and sharing it across the organization (Lanzara and Patriotta 2001; Nonaka and Takeuchi 1995). Of the socialization dimensions, persistent interactions among organizational members are the most important to knowledge transfer and sharing (Argote and Fahrenkopf 2016; Lanzara and Patriotta 2001; Paruchuri and Awate 2017).

Strong ties refer to closeness in the relationship or frequent interactions among members in the network structure (Granovetter 1973; Hansen 1999). In general, strong ties work as a conduit through which useful knowledge flows (Aral 2016; Hansen 1999; Szulanski 1996; Uzzi 1997) and makes access to useful knowledge easy (Krackhardt 1992) from the members' perspective. Additionally, strong ties among members promote trust (Reagans and McEvily 2003). Trust is an important mechanism that reduces risks from knowledge 
appropriation and misuse to members willing to share knowledge, thereby activating knowledge transfer and sharing (Krackhardt 1990; McEvily et al. 2003).

However, the positive role of weak ties in knowledge sharing has been researched (Granovetter 1973; Rogers 1995; Uzzi and Lancaster 2003). While weak ties can be advantageous to knowledge exploration or sharing of simple knowledge, they may be inappropriate for transferring complicated knowledge as a precondition for sharing such knowledge (Hansen 1999). This is because complicated knowledge requires a high level of commitment and substantial time from both the knowledge giver and receiver. It is unlikely that knowledge transfer would take place in a dyadic relationship characterized by weak ties.

The second hypothesis is as follows:

Hypothesis 2. As the between-subgroup network strength of a focal subgroup increases, the focal subgroup would have a higher frequency of knowledge sharing with other subgroups.

\subsection{Within-Subgroup Network Strength}

According to social psychology research (e.g., Brewer 1979), individuals overvalue members of the same group and undervalue members of different groups. The likelihood of in-group bias increases as the strength of relations among in-group members increases (Hansen et al. 2005). Likewise, it is inferred that a group with a strong in-group bias would overvalue its alternatives and undervalue alternatives from outside the group. Thus, the group is less likely to properly evaluate valuable opportunities or useful information and knowledge from external sources. Additionally, the self-reinforcing nature of strong relationships among members would strengthen the in-group bias. In their study on R\&D teams, Katz and Allen (1982) empirically showed that members of the same working group overvalue knowledge in their possession and undervalue knowledge from external sources. The tendency of overvaluation of internal knowledge, called not-invented-here $(\mathrm{NIH})$ syndrome, demonstrates that in-group bias is prevalent across knowledge-based organizations (Yoon and Han 2017). A group with strong NIH syndrome would be less likely to utilize knowledge outside the group, even when it has the opportunity (Grigoriou and Rothaermel 2017).

A strong relationship among group members can enhance in-group problem-solving competency and establish a common knowledge base for group members (Uzzi 1997). Social interactions based on this strong relationship would be advantageous for the integration of competencies within the group and actively sharing knowledge with group members, but could reduce opportunities to explore alternatives outside the group (Hansen et al. 2005; Inkpen and Tsang 2005). Furthermore, group closure formed by the strong relationship promotes identification with the group members (Portes and Sensenbrenner 1993; Yoon et al. 2016) and reinforces exchange relationships and collective action ( Coleman 1988). Social interactions based on group identification can reduce the costs of maintaining and defending the group's resources and knowledge through shared emotions or affect. However, they can be disadvantageous when the group needs to acquire differentiated knowledge. Therefore, it is argued that in the case of strong within-group network strength, given its between-group network size, a group would be less likely to acquire useful information and knowledge outside the group. However, in the case of weak within-group network strength, a group would have sufficient incentive to acquire such resources because it does not have any psychological or relational constraints. Hence, as within-group network strength increases, the relationship of between-group network size and knowledge sharing may become negative.

The last hypothesis is as follows:

Hypothesis 3. Within-group network strength of a focal subgroup negatively moderates the effect of the between-subgroup network size on knowledge sharing.

In summary, Figure 1 provides our research model and hypotheses. 


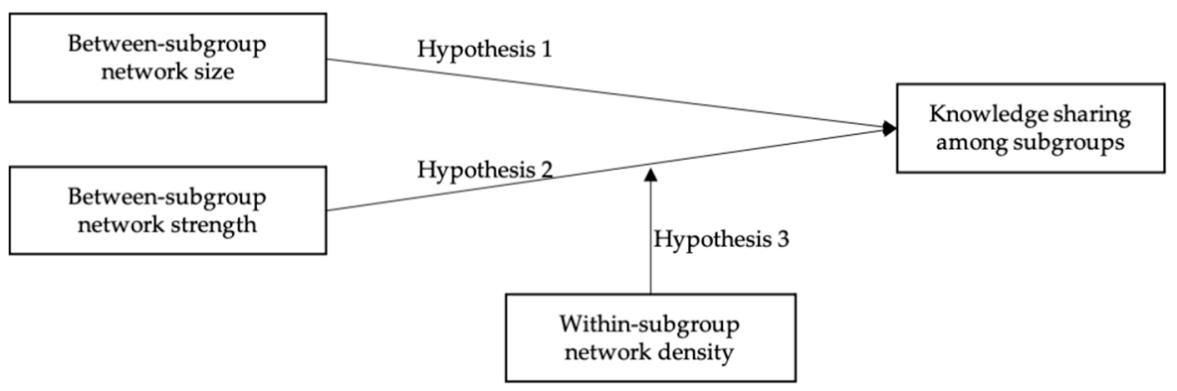

Figure 1. Research model and hypotheses.

\section{Methods}

\subsection{Sample and Procedure}

Data for this study were collected from a paint manufacturing company in the Gyeonggi Province, South Korea. The company, founded in 1945, has been consistently ranked as one of the top five companies in the paint manufacturing industry of South Korea. The company is not exceptional compared to its competitors in terms of its organizational structure, production facilities, and management style. Our target sample consisted of 762 employees, including 69 team leaders. The company provided archival data on employees' names and demographic characteristics, allowing us to conduct online surveys and employee interviews. The online survey was conducted for three weeks in May 2019.

On behalf of our research team, the human resource (HR) team sent an email to the employees emphasizing that the third party would administer the online survey. Survey participation was completely voluntary with an assurance of complete confidentiality and anonymity. Employees who agreed to participate in the survey were invited through a link to our opt-in online survey system in the email. The HR team sent two survey reminder emails with the team's survey progress rate for the three weeks to encourage survey participation. Additionally, electronic gift cards of approximately USD 10 in value were given to 30 employees selected from a random drawing after survey closure.

Two different online surveys were created: one for team members and the other for team leaders. Each of the online surveys consisted of two parts. The first part included survey items for core self-evaluation and the frequency of knowledge sharing with other teams. The second part included survey items to measure advice networks among the team members using the full roster method (Marsden 1990). The team leaders' survey included survey items for between-subgroup networks, tertius iungens orientation, and team competition. The survey participants' demographic information (e.g., age, gender, tenure, education level, job title and rank, team, business unit) was obtained from the HR team's archival data.

Of the 762 employees, 642 completed the team member survey, yielding a survey response rate of $84.3 \%$ at the individual level. Teams in which half of the team members did not complete the survey were excluded from the analysis. Consequently, 58 teams' $(84.1 \%)$ and 536 employees' (70.3\%) responses were used for the analysis. In our sample, $89.9 \%$ were men in teams, the average team tenure was 13.2 years (s.d. 3.3), 74.3\% had university degrees, and $10.7 \%$ had graduate degrees. The average team size was 9.24 (s.d. 6.5), ranging from 3 to 44 members. Of the total 58 teams, 35 teams had three to eight members, 21 teams 9 to 19 members, and two teams in the manufacturing unit had more than 30 members working on shift.

\subsection{Measurement}

Although cross-sectional in nature, this study employed a multi-informant survey design to minimize the common method variances among the key variables. Knowledge sharing as a dependent variable was obtained from team members and team leaders, between-subgroup network size and strength as independent variables from team leaders only, within-subgroup network strength as a moderator from team members (see Ap- 
pendix A for details), and team characteristics as control variables from the company's archival data.

\subsubsection{Dependent Variable}

Knowledge sharing was measured with the frequency of knowledge sharing developed by Cummings (2004) to capture the extent to which knowledge sharing occurred among teams within the company. After consulting with the company's HR and operation staff, we identified five types of knowledge required to perform tasks and measured the frequency of knowledge sharing with other team members: (1) general knowledge about routine tasks, (2) professional knowledge and skills, (3) problem-solving methods, (4) task progress, and (5) task results. Team members were asked to rate: "On average, how often did you share each type of knowledge with organizational members in other teams?" (1 "never"; 2 "rarely"; 3 "sometimes"; 4 "regularly"; 5 "a lot"). We computed the average of the five ratings by number of team members to measure knowledge sharing at the team level.

\subsubsection{Independent Variables}

Between-subgroup network size and strength were measured with the items used by Hansen et al. (2005). To test Hypothesis 1, we asked each team leader to check, "Over the last two years, are there any teams from whom your team regularly asked and acquired technical input?" The list of 69 teams followed the question. We computed the betweensubgroup network size as the number of between-subgroup relations that each team received from other teams divided by the number of analyzed teams minus one.

For each of the relations each team leader checked on the list, he/she was further asked to rate the following: "How close is the working relationship between your team and this team?" (1 "not very close"; 2 "not close"; 3 "neutral"; 4 "close"; 5 "very close"). We used the rating as the between-subgroup network strength to test Hypothesis 2.

The within-team network density was used as the proxy for within-subgroup network strength, the moderating variable. To test Hypothesis 3, we asked each team member to check: "Over the last six months, are there any persons in your team from whom you regularly sought information and advice for your tasks?" The list of team members followed the question. We computed the within-team network density as the number of relations he/she received from other team members divided by the number of all possible relations within teams. This measure ranges from 0 ("no relations") to 1 ("all possible relations exist").

\subsubsection{Control Variable}

We controlled for several team characteristics that are known to affect knowledge sharing at the team level. We first entered a couple of team demographic variables to control for teams' inclination to seek knowledge outside their boundaries. Team size was included to indicate a team's capacity to absorb external knowledge and dispense with internal knowledge (Tsai 2002). Team size was measured by the total number of team members who completed the online survey for each team. Team tenure was included because prior research showed that team tenure is negatively associated with a team's outside help-seeking behavior (e.g., Katz and Allen 1982). Similarly, it is likely that team tenure negatively affects the team's seeking and sharing of external knowledge. Team tenure was calculated by taking the mean of the number of years the individual team members had been with the company.

We also included team gender and the educational composition of the model. Team gender was calculated by taking the mean of the gender category ( 1 : male, 0 : female) of individual team members. As for team educational compositions, we first categorized each team member's final education level into high school graduates, college or university degree, and graduate degree and computed each educational level (high school graduates as a reference group). Additionally, the standard deviations of team tenure and gender 
were included to control for the effect of team diversity on knowledge sharing (Cummings 2004; Levin and Cross 2004). Finally, to control for teams' general task characteristics, we categorized business units into management, $R \& D$, distribution, and operation. Business units were coded as dummy variables (management unit as a reference group).

We also included three unobservable team properties, measured using team members' and team leaders' ratings. First, the team's competition was measured using two items from Tsai (2001). For example, team leaders were asked to rate: "Our team has strongly competing team(s) in the firm" (1 = "strongly disagree"; 2 = "disagree"; 3 = "Neutral"; $4=$ "agree"; 5 = "strongly agree"). Second, team core self-evaluation and team leader's tertius iungens orientation were included because they are likely to affect knowledge sharing. Core self-evaluation refers to how individuals broadly evaluate themselves and their relationship with their environment across situations (Judge et al. 1998). The higher the score for self-evaluation, the more individuals think that they can achieve the company's goals by changing the external environment or their behaviors (Johnson et al. 2008). Likewise, higher team core self-evaluation indicates that team members have strong beliefs about their abilities and are motivated toward team achievement (Judge and Hurst 2008). Therefore, a team with a high team core self-evaluation is expected to acquire external knowledge to improve team performance actively. We first measured each team members' core self-evaluation with 12 items from the Core Self-Evaluation Scale (CSES) on a 5-point scale ( 1 = "strongly disagree"; 2 = "disagree"; 3 = "Neutral"; $4=$ "agree"; 5 = "strongly agree") and then, used the mean of the core self-evaluation by the team as team core self-evaluation. Finally, tertius iungens orientation refers to a strategic orientation that connects unknown people and creates cooperation among them by coordinating their interests (Obstfeld 2005). Team leaders with high tertius iungens orientation are likely to induce cooperation among team members and develop mutually reciprocal relationships. Therefore, a team leader's tertius iungens orientation may have a positive effect on knowledge sharing. Team leaders were asked to rate their tertius iungens orientation with 6 items on a 5 points scale $(1=$ "strongly disagree"; $2=$ "disagree"; $3=$ "neutral"; $4=$ "agree"; $5=$ "strongly agree") (Obstfeld 2005). A sample item is "I introduce people to each other who might have a common strategic work interest." Data for this study were collected from a chemical company in the Gyeonggi Province, South Korea. Our target sample consisted of 762 employees, including 69 team leaders. The company provided archival data on employees' names and demographic characteristics, allowing us to conduct online surveys and employee interviews.

\section{Results}

Table 1 presents the descriptive statistics and correlations for the study variables at the team level. The internal consistency reliabilities of the measured variables (i.e., team competition, team core self-evaluation, team leader's tertius iungens orientation, and knowledge sharing among teams) were greater than 0.79 , which is beyond the acceptable threshold. As for the correlations among the key variables, knowledge sharing among teams had no statistically significant correlation with between-subgroup network size $(\mathrm{r}=$ $-0.18)$ and between-subgroup network strength $(\mathrm{r}=0.19)$, but was significantly correlated with within-subgroup network strength $(r=0.33, p<0.05)$. Additionally, there was a statistically significant correlation with team core self-evaluation $(r=0.53, p<0.001)$ and with the team leader's tertius iungens orientation $(r=0.26, p<0.05)$. 
Table 1. Means, standard deviations, and correlations of variables.

\begin{tabular}{|c|c|c|c|c|c|c|c|c|c|c|c|}
\hline Variables & $\mathbf{M}$ & SD & 1 & 2 & 3 & 4 & 5 & 6 & 7 & 8 & 9 \\
\hline 1. Team size & 9.24 & 6.49 & & & & & & & & & \\
\hline 2. Team gender (Mean) & 0.90 & 0.12 & 0.12 & & & & & & & & \\
\hline 3. Team gender (s.d.) & 0.21 & 0.21 & -0.14 & -0.91 & & & & & & & \\
\hline 5. Team tenure (s.d.) & 7.82 & 1.64 & 0.28 & -0.03 & -0.03 & 0.48 & & & & & \\
\hline 6. High school degree & 0.15 & 0.23 & 0.54 & 0.23 & -0.20 & 0.54 & 0.41 & & & & \\
\hline 7. University degree & 0.74 & 0.25 & -0.42 & -0.21 & 0.25 & -0.46 & -0.21 & -0.67 & & & \\
\hline 8. Graduate degree & 0.11 & 0.20 & -0.09 & 0.00 & -0.09 & -0.03 & -0.21 & -0.31 & -0.51 & & \\
\hline 10. R\&D unit & 0.21 & 0.41 & -0.10 & 0.12 & -0.17 & -0.03 & -0.04 & -0.33 & -0.12 & 0.53 & -0.37 \\
\hline 11. Distribution unit & 0.22 & 0.42 & -0.12 & -0.29 & 0.38 & -0.32 & 0.00 & 0.02 & 0.16 & -0.22 & -0.39 \\
\hline 12. Operation unit & 0.22 & 0.42 & 0.43 & 0.35 & -0.36 & 0.63 & 0.35 & 0.79 & -0.50 & -0.27 & -0.39 \\
\hline 13. Team Competition & 3.35 & 0.71 & -0.06 & -0.16 & 0.21 & 0.03 & 0.07 & 0.05 & 0.08 & -0.16 & -0.20 \\
\hline 14. Team core self-evaluation & 3.56 & 0.21 & -0.16 & 0.02 & -0.04 & -0.06 & -0.03 & -0.21 & 0.31 & -0.16 & 0.11 \\
\hline 15. Leader tertius iungens orientation & 4.11 & 0.53 & -0.17 & -0.07 & 0.08 & -0.21 & -0.23 & -0.28 & 0.23 & 0.03 & 0.06 \\
\hline 16. Knowledge-sharing among teams & 4.08 & 0.26 & -0.18 & 0.09 & -0.03 & -0.06 & 0.01 & -0.20 & 0.28 & -0.13 & -0.15 \\
\hline 17. Between-subgroup network size & 0.25 & 0.11 & 0.13 & -0.05 & 0.02 & 0.12 & 0.27 & -0.02 & 0.12 & -0.12 & 0.05 \\
\hline $\begin{array}{l}\text { 18. Between-subgroup } \\
\text { network strength }\end{array}$ & 3.87 & 0.26 & -0.05 & -0.01 & -0.05 & -0.11 & -0.12 & 0.05 & -0.14 & 0.12 & -0.22 \\
\hline $\begin{array}{l}\text { 19. Within-subgroup } \\
\text { network strength }\end{array}$ & 0.44 & 0.22 & -0.30 & 0.08 & -0.11 & -0.08 & -0.11 & -0.32 & 0.14 & 0.19 & -0.10 \\
\hline 11. Distribution unit & & & $\begin{array}{c}10 \\
-0.28\end{array}$ & 11 & 12 & 13 & 14 & 15 & 16 & 17 & 18 \\
\hline 12. Operation unit & & & -0.28 & -0.29 & & & & & & & \\
\hline 13. Team Competition & & & -0.16 & 0.41 & -0.03 & $(0.80)$ & & & & & \\
\hline 14. Team core self-evaluation & & & 0.12 & -0.18 & -0.07 & -0.26 & $(0.85)$ & & & & \\
\hline 15. Leader tertius iungens orientation & & & 0.06 & 0.08 & -0.20 & 0.01 & 0.11 & $(0.89)$ & & & \\
\hline 16. Knowledge-sharing among teams & & & 0.21 & 0.08 & -0.11 & -0.09 & 0.53 & 0.26 & $(0.93)$ & & \\
\hline 17. Between-subgroup network size & & & 0.20 & -0.32 & 0.07 & -0.06 & 0.10 & -0.10 & -0.18 & & \\
\hline $\begin{array}{l}\text { 18. Between-subgroup } \\
\text { network strength }\end{array}$ & & & -0.02 & 0.18 & 0.09 & -0.08 & -0.18 & 0.03 & 0.19 & -0.44 & \\
\hline $\begin{array}{l}\text { 19. Within-subgroup } \\
\text { network strength }\end{array}$ & & & 0.47 & -0.17 & -0.17 & -0.07 & 0.30 & 0.17 & 0.33 & -0.03 & 0.03 \\
\hline
\end{tabular}

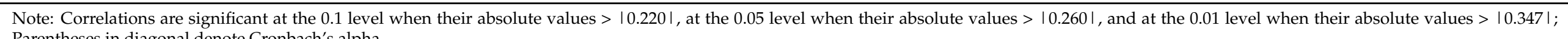

Parentheses in diagonal denote Cronbach's alpha. 
Table 2 presents the results of the hierarchical regression for hypothesis testing. Only the control variables were included in Model 1, and between-subgroup network size and strength were added in Model 2. The interaction term of between-subgroup network size with within-subgroup network strength was added to Model 3.

Table 2. Hierarchical regression of knowledge sharing on informal network structure.

\begin{tabular}{|c|c|c|c|}
\hline Variables & Model 1 & Model 2 & Model 3 \\
\hline Team size & $\begin{array}{l}-0.00 \\
(0.01)\end{array}$ & $\begin{array}{c}0.00 \\
(0.01)\end{array}$ & $\begin{array}{l}-0.00 \\
(0.01)\end{array}$ \\
\hline Team gender (Mean) & $\begin{array}{c}0.86 \\
(0.67)\end{array}$ & $\begin{array}{l}1.09+ \\
(0.62)\end{array}$ & $\begin{array}{c}0.71 \\
(0.62)\end{array}$ \\
\hline Team gender (s.d.) & $\begin{array}{c}0.37 \\
(0.38)\end{array}$ & $\begin{array}{c}0.54 \\
(0.36)\end{array}$ & $\begin{array}{c}0.42 \\
(0.34)\end{array}$ \\
\hline Team tenure (Mean) & $\begin{array}{c}0 \\
(0.01)\end{array}$ & $\begin{array}{c}0.01 \\
(0.01)\end{array}$ & $\begin{array}{c}0 \\
(0.01)\end{array}$ \\
\hline Team tenure (s.d.) & $\begin{array}{c}0.02 \\
(0.02)\end{array}$ & $\begin{array}{c}0.03 \\
(0.02)\end{array}$ & $\begin{array}{c}0.03 \\
(0.02)\end{array}$ \\
\hline University degree & $\begin{array}{c}0.21 \\
(0.27)\end{array}$ & $\begin{array}{c}0.22 \\
(0.25)\end{array}$ & $\begin{array}{c}0.14 \\
(0.24)\end{array}$ \\
\hline Graduate degree & $\begin{array}{c}0.05 \\
(0.33)\end{array}$ & $\begin{array}{c}-0.07 \\
(0.3)\end{array}$ & $\begin{array}{c}-0.22 \\
(0.3)\end{array}$ \\
\hline R\&D unit & $\begin{array}{l}0.13 \\
(0.1)\end{array}$ & $\begin{array}{l}0.16 \\
(0.1)\end{array}$ & $\begin{array}{l}0.26 * \\
(0.11)\end{array}$ \\
\hline Distribution unit & $\begin{array}{l}0.17 \\
(0.1)\end{array}$ & $\begin{array}{l}0.05 \\
(0.1)\end{array}$ & $\begin{array}{l}0.07 \\
(0.1)\end{array}$ \\
\hline Operation unit & $\begin{array}{c}0.08 \\
(0.15\end{array}$ & $\begin{array}{c}0 \\
(0.14)\end{array}$ & $\begin{array}{c}0.06 \\
(0.14)\end{array}$ \\
\hline Team competition & $\begin{array}{l}-0.03 \\
(0.05)\end{array}$ & $\begin{array}{l}-0.00 \\
(0.05)\end{array}$ & $\begin{array}{c}0.01 \\
(0.04)\end{array}$ \\
\hline Team core self-evaluation & $\begin{array}{c}0.54^{* *} \\
(0.17)\end{array}$ & $\begin{array}{c}0.61^{* * *} \\
(0.15)\end{array}$ & $\begin{array}{c}0.71^{* * *} \\
(0.15)\end{array}$ \\
\hline Leader tertius iungens orientation & $\begin{array}{c}0.09 \\
(0.06))\end{array}$ & $\begin{array}{c}0.08 \\
(0.06)\end{array}$ & $\begin{array}{l}0.11+ \\
(0.05)\end{array}$ \\
\hline Within-subgroup network strength & $\begin{array}{l}0.15 \\
(0.17\end{array}$ & $\begin{array}{c}0.08 \\
(0.16)\end{array}$ & $\begin{array}{l}-0.07 \\
(0.16)\end{array}$ \\
\hline Between-subgroup network size & & $\begin{array}{l}-0.47 \\
(0.32)\end{array}$ & $\begin{array}{l}-0.43 \\
(0.31)\end{array}$ \\
\hline Between-subgroup network strength & & $\begin{array}{l}0.27 * \\
(0.13)\end{array}$ & $\begin{array}{l}0.26 * \\
(0.12)\end{array}$ \\
\hline $\begin{array}{l}\text { Between-subgroup network size } \\
\text { Within-subgroup network strength }\end{array}$ & & & $\begin{array}{l}-3.23 * \\
(1.42)\end{array}$ \\
\hline Intercept & $\begin{array}{c}2.82 * * * \\
(0.78)\end{array}$ & $\begin{array}{c}2.47^{* *} \\
(0.73)\end{array}$ & $\begin{array}{c}2.92 * * * \\
(0.72)\end{array}$ \\
\hline$N$ & 58 & 58 & 58 \\
\hline d.f & 14 & 16 & 17 \\
\hline$R^{2}$ & 0.45 & 0.56 & 0.61 \\
\hline$\Delta P^{2}$ & & 0.11 & 0.05 \\
\hline$F$-value & 2.5 & 3.24 & 3.67 \\
\hline
\end{tabular}

Note: $+p<0.10,{ }^{*} p<0.05,{ }^{* *} p<0.01,{ }^{* * *} p<0.001$. 
Model 1 shows that only the team core self-evaluation was positive and statistically significant with knowledge sharing $(b=0.54, p<0.001)$.

Model 2 presents the results of testing Hypotheses 1 and 2. The coefficient on the between-subgroup network size was negative, against our prediction, but not statistically significant $(b=-0.47, p>0.10)$, indicating that Hypothesis 1 was rejected. The coefficient on the between-subgroup network strength was positive and statistically significant $(b=0.27$, $p<0.05)$, thus confirming Hypothesis 2 . The inclusion of these two variables in Model 2 significantly increased the R-squared value by 0.110 (F-value $=5.09, p<0.05)$. This also affected the significance level of the control variables. For example, the mean of team gender became statistically significant $(b=1.09, p<0.1)$, while team core self-evaluation remained statistically significant $(b=0.61, p<0.001)$. Model 3 presents a significant interaction between subgroup network size and within-subgroup network strength, indicating that the relationship between between-subgroup network size and knowledge-sharing was negatively moderated by within-subgroup network strength $(b=-3.23, p<0.05)$. The inclusion of the interaction term in Model 3 also significantly increased R-squared by 0.05 (F-value $=5.200, p<0.05)$, thus supporting Hypothesis 3.

We plotted this interaction following West et al. (1996) to examine the direction of this effect.

As shown in Figure 2, between-subgroup network size was positively (negatively) related to knowledge sharing only under low (high) within-subgroup network strength, consistent with our hypothesis.

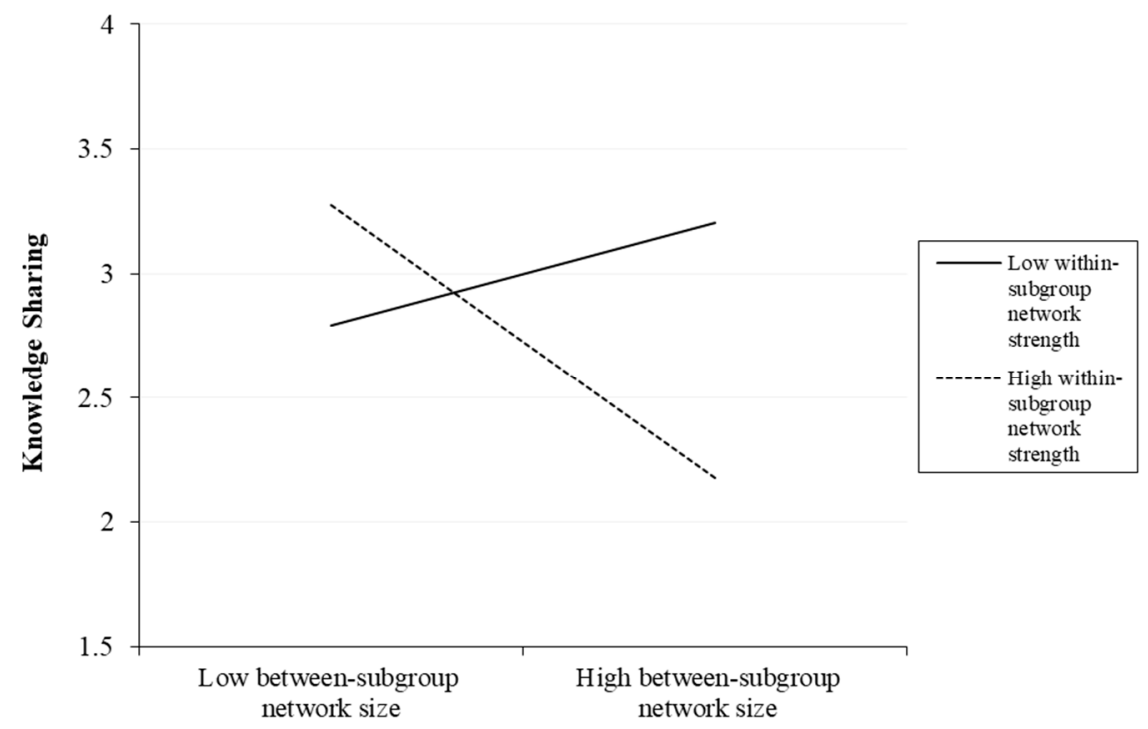

Figure 2. Interaction effect of within-subgroup network strength on the relationship between the size of between- subgroup network and knowledge sharing.

\section{Discussion}

This study examined the effects of between-subgroup network size and strength on knowledge sharing among other subgroups and the moderating effect of within-subgroup network strength on the relationship of between-subgroup network size with knowledge sharing. We tested the above relationships using a sample of 58 teams in a chemical company in South Korea.

The results of this study can be divided into three parts. First, this study did not find that between-subgroup network size positively affected knowledge sharing with other subgroups. The results suggest that expanding a common knowledge base or raising awareness about external knowledge per se may not directly affect external knowledge sharing. This implies that informal networks expand the common knowledge base or raise awareness about external knowledge but do not enhance absorptive capacity or learning ability. Future research should incorporate absorptive capacity or learning into an 
empirical model and examine how these factors and between-subgroup network size affect knowledge sharing with other subgroups.

Second, this study demonstrated the positive effect of between-subgroup network strength on external knowledge sharing, indicating the advantages of strong ties among subgroups (e.g., Hansen 1999; Reagans and McEvily 2003). This result suggests that the advantages of weak ties are limited to sharing simple knowledge. More direct, strong relationships among actors are required for sharing complicated knowledge. It will be meaningful if future research considers knowledge sharing characteristics not considered in this study. This result also suggests that although knowledge exploration is advantageous, weak ties, a necessary condition for knowledge sharing, may not be appropriate. Future research needs to further examine the roles of network strength in each stage of the process of "knowledge exploration, knowledge transfer, and knowledge sharing".

Third, this study also provided evidence that within-subgroup network strength negatively moderates the relationship of between-subgroup network size with external knowledge sharing, indicating the advantages of weak ties among subgroup members (e.g., Granovetter 1973; Rogers 1995; Uzzi and Lancaster 2003). The finding that strong ties among subgroup members would reduce the opportunity for knowledge acquisition obtained by between-subgroup network size provides an important implication for designing a proper organizational structure. For example, when management creates a project team whose essential tasks are to explore external knowledge, this finding suggests that the team should be composed of such members that their homogeneity is not too high to achieve its goals.

These findings emphasize the importance of social networks in promoting external knowledge sharing. That is, social capital, accumulated in social networks at the organization's subgroups and at the individual members of each subgroup, facilitates knowledge sharing. They also provide a practical implication that for effective development of human capital, organizational members should be encouraged to form strong ties with members from other subgroups, but not too strong ties with the same subgroup members.

On the other hand, companies have responded to the recent COVID-19 pandemic by utilizing various work arrangements, such as remote work or work at home. However, these flexible work arrangements would have affected the traditional ways of knowledge sharing among members by restricting opportunities for them to form and maintain social ties. There is no empirical study on how COVID-19 affects external knowledge sharing among members to the best of our knowledge. In this regard, it would be interesting to investigate how various work arrangements affect knowledge sharing and provide implications for employers to ensure continuous and effective knowledge sharing among employees. In addition, previous research on knowledge sharing has identified cognitive job demands, job autonomy (Gagné et al. 2019), organizational justice, perceived organizational support, and affective organizational commitment (Cugueró-Escofet et al. 2019) as individual-level determinants, and organizational culture (Oyemomi et al. 2019) and ethical leadership (Liu et al. 2019) as organization-level determinants. Future research can extend the literature by investigating how such variables interact with social networks in knowledge sharing.

Our study has several limitations. First, this study only focuses on work-related networks. In previous research on social networks, two types of networks have been identified: instrumental and expressive networks. Each type conveys different network contents (e.g., Fombrun 1982; Ibarra 1995; Podolny and Baron 1997; Umphress et al. 2003). Instrumental ties are based on information and cognition, while expressive ties are based on normative and affect (Umphress et al. 2003). This study focused on the instrumental network, as it explored how work-related knowledge is shared across subgroups. However, it would be more helpful to understand the mechanism of between-subgroup knowledge sharing in organizations if these two types of networks are considered simultaneously. Further research is needed to compare the effects of the two types of social networks on organizations' knowledge sharing. 
Second, this study used a cross-sectional design. For example, it is possible that external knowledge sharing affects between-subgroup network size and strength. However, past research has suggested that this reverse causality is unlikely (Hansen et al. 2005; Levin and Cross 2004). Additionally, a cross-sectional research design is often vulnerable to common method bias when the same informants simultaneously measure the independent and dependent variables. We measured network variables using the full roster method and knowledge sharing by aggregating survey responses from team members. Separate measurements for key informants help mitigate potential common method bias.

Third, this study did not consider the potential functional differences of subgroups in the organization. The subgroups may be designated to differ by their motivation to pursue and achieve knowledge sharing, and therefore, have different mechanisms toward knowledge sharing. Our analysis, however, assumed them to be functionally equivalent in knowledge sharing. It would be interesting if future research could examine this limitation with functionally equivalent subgroups across companies.

Despite these limitations, this study's findings provide significant theoretical and practical implications for the literature on external knowledge sharing by exploring the potentially heterogeneous roles of multiple subsets of informal networks in an organization. The findings differ from those of previous research. Strong ties among subgroups and weak ties among subgroup members play significant roles in promoting external knowledge sharing in the organization. Thus, this study highlights that certain nodes in a network are often simultaneously located in different networks at various levels within an organization and function as a context for being inclusive of different networks.

\section{Conclusions}

The study's findings provide significant theoretical and practical implications for the literature on external knowledge sharing by exploring the potentially heterogeneous roles of multiple subsets of informal networks in an organization. The study empirically evidenced the positive and significant effect of between-subgroup network strength on knowledge sharing among other subgroups and the negative and significant moderating effect of within-subgroup network strength on the relationship of between-subgroup network size with external knowledge sharing. Overall, this study's findings differ from those of previous research in that strong ties among subgroups and weak ties among subgroup members played significant roles in promoting external knowledge sharing in the organization. Thus, this study highlights that certain nodes in a network are often simultaneously located in different types of networks that exist at various levels within an organization and function as a context for being inclusive of different types of networks.

Author Contributions: Conceptualization, W.Y. and K.W.P.; methodology, W.Y., K.W.P. and J.J.; software, J.J.; validation, K.W.P. and J.J.; formal analysis, J.J.; investigation, K.W.P.; resources, W.Y.; data curation, J.J.; writing—original draft preparation, W.Y.; writing-review and editing, K.W.P. and J.J.; visualization, J.J.; supervision, W.Y.; project administration, K.W.P. and J.J.; funding acquisition, W.Y. All authors have read and agreed to the published version of the manuscript.

Funding: This work was supported by the Ministry of Education of the Republic of Korea and the National Research Foundation of Korea (NRF-2018S1A5A2A01029450) to W.Y.

Institutional Review Board Statement: Not applicable.

Informed Consent Statement: Not applicable.

Data Availability Statement: The data will be made available on request from the corresponding author.

Conflicts of Interest: The authors declare no conflict of interest. 


\section{Appendix A Survey Items for the Key Variables}

Knowledge-sharing among teams

On average, how often did you share each type of knowledge with organizational members in other teams?

( 1 "never"; 2 "rarely"; 3 "sometimes"; 4 "regularly"; 5 "a lot")

(1) general knowledge about routine tasks

(2) professional knowledge and skills

(3) problem-solving methods

(4) task progress

(5) task results

Between-subgroup network size

Over the last two years, are there any teams from whom your team regularly asked and acquired technical input?

Between-subgroup network strength

How close is the working relationship between your team and this team?

( 1 "not very close"; 2 "not close"; 3 "neutral"; 4 "close"; 5 "very close")

Within-team network density

Over the last six months, are there any persons in your team from whom you regularly sought information and advice for your tasks?

Core-self evaluation

(1 "strongly disagree"; 2 "disagree"; 3 "neutral"; 4 "agree"; 5 "Strongly agree")

(1) I am confident I get the success I deserve in life.

(2) Sometimes I feel depressed.

(3) When I try, I generally succeed.

(4) Sometimes when I fail I feel worthless.

(5) I complete tasks successfully.

(6) Sometimes, I do not feel in control of my work.

(7) Overall, I am satisfied with myself.

(8) I am filled with doubts about my competence.

(9) I determine what will happen in my life.

(10) I do not feel in control of my success in my career.

(11) I am capable of coping with most of my problems.

(12) There are times when things look pretty bleak and hopeless to me.

Team competition agree").

( 1 = "strongly disagree"; 2 = "disagree"; 3 = "Neutral"; 4 = "agree"; 5 = "strongly

(1) Competition is intense among teams in the firm

(2) Our team has strongly competing team(s) in the firm

Team leader's tertius iungens orientation agree")

$(1=$ "strongly disagree"; 2 = "disagree"; 3 = "neutral"; 4 = "agree"; 5 = "strongly

(1) I introduce people to each other who might have a common strategic work interest.

(2) I will try to describe an issue in a way that will appeal to a diverse set of interests.

(3) I see opportunities for collaboration between people.

(4) I point out the common ground shared by people who have different perspectives on an issue.

(5) I introduce two people when I think they might benefit from becoming acquainted.

(6) I forge connections between different people dealing with a particular issue. 


\section{References}

Adler, Paul S., and Seok-Woo Kwon. 2002. Social capital: Prospects for a new concept. Academy of Management Review 27: 17-40. [CrossRef]

Albers, Sascha, Franz Wohlgezogen, and Edward J. Zajac. 2016. Strategic alliance structures: An organization design perspective. Journal of Management 42: 582-614. [CrossRef]

Almeida, Paul, and Bruce Kogut. 1999. Localization of knowledge and the mobility of engineers in regional networks. Management Science 45: 905-17. [CrossRef]

Almeida, Paul, Jaeyong Song, and Robert M. Grant. 2002. Are firms superior to alliances and markets? An empirical test of cross-border knowledge building. Organization Science 13: 147-61. [CrossRef]

Aral, Sinan. 2016. The future of weak ties. American Journal of Sociology 121: 1931-39. [CrossRef]

Argote, Linda, and Erin Fahrenkopf. 2016. Knowledge transfer in organizations: The roles of members, tasks, tools, and networks. Organizational Behavior and Human Decision Processes 136: 146-59. [CrossRef]

Argote, Linda, and Paul Ingram. 2000. Knowledge transfer: A basis for competitive advantage in firms. Organizational Behavior and Human Decision Processes 82: 150-69. [CrossRef]

Audia, Pino G., John H. Freeman, and Paul Davidson Reynolds. 2006. Organizational foundings in community context: Instruments manufacturers and their interrelationship with other organizations. Administrative Science Quarterly 51: 381-419. [CrossRef]

Austin, John R. 2003. Transactive memory in organizational groups: The effects of content, consensus, specialization, and accuracy on group performance. Journal of Applied Psychology 88: 866. [CrossRef] [PubMed]

Beckman, Christine M., Pamela R. Haunschild, and Damon J. Phillips. 2004. Friends or strangers? Firm-specific uncertainty, market uncertainty, and network partner selection. Organization Science 15: 259-75. [CrossRef]

Bourdieu, Pierre. 1986. The forms of capital. In Handbook of Theory and Research for the Sociology of Education. Edited by John Richardson. New York: Greenwood Press, pp. 241-58.

Brewer, Marilynn B. 1979. In-group bias in the minimal intergroup situation: A cognitive-motivational analysis. Psychological Bulletin 86: 307-24. [CrossRef]

Burt, Ronald S. 1992. Structural Holes: The Social Structure of Competition. Cambridge: Harvard University Press.

$\mathrm{Chu}$, Youngeun, and Woojin Yoon. 2020a. The imprinting effect of initial conditions on the configuration of dual distribution in franchising companies. Journal of Innovation \& Knowledge 5: 175-78.

Chu, Youngeun, and Woojin Yoon. 2020b. Tech start-ups: Networking strategies for better performance. Journal of Business Strategy. [CrossRef]

Chu, Youngeun, and Woojin Yoon. 2021. Organizational status change of joint venture: The buyout by one parent. International Journal of Economics and Business Administration 9: 57-66. [CrossRef]

Chung, Jee Yong, and Woojin Yoon. 2020. Technological capabilities and internationalization of high-tech ventures: The moderating role of strategic orientations. Managerial and Decision Economics 41: 1462-72. [CrossRef]

Cohen, Wesley M., and Daniel A. Levinthal. 1990. Absorptive capacity: A new perspective on learning and innovation. Administrative Science Quarterly 35: 128-52. [CrossRef]

Coleman, James S. 1988. Social capital in the creation of human capital. American Journal of Sociology 94: S95-S120. [CrossRef]

Coleman, James S. 1990. Foundations of Social Theory. Cambridge: Harvard University Press.

Cugueró-Escofet, Natàlia, Pilar Ficapal-Cusí, and Joan Torrent-Sellens. 2019. Sustainable Human Resource Management: How to Create a Knowledge Sharing Behavior through Organizational Justice, Organizational Support, Satisfaction and Commitment. Sustainability 11: 5419. [CrossRef]

Cummings, Jonathon N. 2004. Work groups, structural diversity, and knowledge sharing in a global organization. Management Science 50: 352-64. [CrossRef]

Farjoun, Moshe. 1998. The independent and joint effects of the skill and physical bases of relatedness in diversification. Strategic Management Journal 19: 611-30. [CrossRef]

Ferrin, Donald L., Kurt T. Dirk, and Pri P. Shah. 2006. Direct and indirect effects of third-party relationships on interpersonal trust. Journal of Applied Psychology 91: 870-83. [CrossRef]

Fombrun, Charles J. 1982. Strategies for network research in organizations. Academy of Management Review 7: 280-91. [CrossRef]

Foss, Nicolai J., and Torben Pedersen. 2019. Microfoundations in international management research: The case of knowledge sharing in multinational corporations. Journal of International Business Studies 50: 1594-621. [CrossRef]

Gagné, Marylène, Amy Wei Tian, Christine Soo, Bo Zhang, Khee Seng Benjamin Ho, and Katrina Hosszu. 2019. Different motivations for knowledge sharing and hiding: The role of motivating work design. Journal of Organizational Behavior 40: 783-99. [CrossRef]

Galbraith, Jay. R. 1973. Designing Complex Organizations. Reading: Addison-Wesley.

Granovetter, Mark S. 1973. The strength of weak ties. American Journal of Sociology 78: 1360-80. [CrossRef]

Grant, Robert M. 1996. Toward a knowledge-based theory of the firm. Strategic Management Journal 17: 109-22. [CrossRef]

Grigoriou, Konstantinos, and Frank T. Rothaermel. 2017. Organizing for knowledge generation: Internal knowledge networks and the contingent effect of external knowledge sourcing. Strategic Management Journal 38: 395-414. [CrossRef]

Gulati, Ranjay. 2007. Managing Network Resources: Alliances, Affiliations and Other Relational Assets. Oxford: Oxford University Press.

Gupta, Anil K., and Vijay Govindarajan. 2000. Knowledge flows within multinational corporations. Strategic Management Journal 21: 473-96. [CrossRef] 
Gupta, Anil K., Vijay Govindarajan, and Ayesha Malhotra. 1999. Feedback-seeking behavior within multinational corporations. Strategic Management Journal 20: 205-22. [CrossRef]

Hansen, Morten T. 1999. The search-transfer problem: The role of weak ties in sharing knowledge across organization subunits. Administrative Science Quarterly 44: 82-111. [CrossRef]

Hansen, Morten T. 2002. Knowledge networks: Explaining effective knowledge sharing in multiunit companies. Organization Science 13: 232-48. [CrossRef]

Hansen, Morten T., Marie Louise Mors, and Bjørn Løvås. 2005. Knowledge sharing in organizations: Multiple networks, multiple phases. Academy of Management Journal 48: 776-93. [CrossRef]

Howard, Michael, H. Kevin Steensma, Marjori Lyles, and Charles Dhanaraj. 2016. Learning to collaborate through collaboration: How allying with expert firms influences collaborative innovation within novice firms. Strategic Management Journal 37: $2092-103$. [CrossRef]

Ibarra, Herminia. 1995. Race, opportunity, and diversity of social circles in managerial networks. Academy of Management Journal 38: 673-703. [CrossRef]

Iftikhar, Rehab, and Tuomas Ahola. 2020. Knowledge sharing in an interorganizational setting: Empirical evidence from the Orange Line metro train project. Journal of Knowledge Management. [CrossRef]

Inkpen, Andrew C., and Eric W. K. Tsang. 2005. Social capital, networks, and knowledge transfer. Academy of Management Review 30: 146-65. [CrossRef]

Johnson, Russell E., Christopher C. Rosen, and Paul E. Levy. 2008. Getting to the core of core self-evaluation: A review and recommendations. Journal of Organizational Behavior 29: 391-413. [CrossRef]

Judge, Timothy A., and Charlice Hurst. 2008. How the rich (and happy) get richer (and happier): Relationship of core self-evaluations to trajectories in attaining work success. Journal of Applied Psychology 93: 849. [CrossRef]

Judge, Timothy A., Edwin A. Locke, Cathy C. Durham, and Avraham N. Kluger. 1998. Dispositional effects on job and life satisfaction: The role of core evaluations. Journal of Applied Psychology 83: 17-34. [CrossRef] [PubMed]

Katz, Ralph, and Thomas J. Allen. 1982. Investigating the Not Invented Here (NIH) syndrome: A look at the performance, tenure, and communication patterns of $50 \mathrm{R} \&$ D Project Groups. RED Management 12: 7-20. [CrossRef]

Kim, Hyeon Chang, and Woojin Yoon. 2019. Study on Types of Technology Cooperation Partner and Innovation Performance: Focusing on Incremental and Radical Innovation. International Journal of Innovation Management 23: 1950005. [CrossRef]

Kogut, Bruce, and Udo Zander. 1992. Knowledge of the firm, combinative capabilities, and the replication of technology. Organization Science 3: 383-97. [CrossRef]

Kogut, Bruce, and Udo Zander. 1996. What firms do? Coordination, identity, and learning. Organization Science 7: 502-18. [CrossRef]

Koka, Balaji R., and John E. Prescott. 2002. Strategic alliances as social capital: A multidimensional view. Strategic Management Journal 23: 795-816. [CrossRef]

Krackhardt, David. 1990. Assessing the political landscape: Structure, cognition, and power in organizations. Administrative Science Quarterly 35: 342-69. [CrossRef]

Krackhardt, David. 1992. The strength of strong ties. In Networks and Organizations: Structure, Form and Action. Edited by Nitin Nohria and Robert G. Eccles. Boston: Harvard Business School Press, pp. 216-39.

Lanzara, Giovan Francesco, and Gerardo Patriotta. 2001. Technology and the courtroom: An inquiry into knowledge making in organizations. Journal of Management Studies 38: 943-71. [CrossRef]

Levin, Daniel Z., and Rob Cross. 2004. The strength of weak ties you can trust: The mediating role of trust in effective knowledge transfer. Management Science 50: 1477-90. [CrossRef]

Liu, Min-Ling, Chieh-Peng Lin, Sheng-Wuu Joe, and Kuang-Jung Chen. 2019. Modeling knowledge sharing and team performance: The interactions of ethical leadership and ambidexterity with politics and job complexity. Management Decision 57: 1472-95. [CrossRef]

Markides, Constantinos C., and Peter J. Williamson. 1994. Related diversification, core competences and corporate performance. Strategic Management Journal 15: 149-65. [CrossRef]

Marsden, Peter V. 1990. Network data and measurement. Annual Review of Sociology 16: 435-63. [CrossRef]

McEvily, Bill, Vincenzo Perrone, and Akbar Zaheer. 2003. Trust as an organizing principle. Organization Science 14: 91-103. [CrossRef]

Nahapiet, Janine, and Sumantra Ghoshal. 1998. Social capital, intellectual capital, and the organizational advantage. Academy of Management Review 23: 242-66. [CrossRef]

Nonaka, Ikujiro, and Hirotaka Takeuchi. 1995. The Knowledge-Creating Company: How Japanese Companies Create the Dynamics of Innovation. New York: Oxford University Press.

Obstfeld, David. 2005. Social networks, the tertius iungens orientation, and involvement in innovation. Administrative Science Quarterly 50: 100-30. [CrossRef]

Owen-Smith, Jason, and Walter W. Powell. 2004. Knowledge networks as channels and conduits: The effects of spillovers in the Boston biotechnology community. Organization Science 15: 5-21. [CrossRef]

Oyemomi, Oluwafemi, Shaofeng Liu, Irina Neaga, Huilan Chen, and Franklin Nakpodia. 2019. How cultural impact on knowledge sharing contributes to organizational performance: Using the fsQCA approach. Journal of Business Research 94: 313-19. [CrossRef]

Park, Hyunjun, Kyungsu Han, and Woojin Yoon. 2018. The impact of cultural distance on the performance of foreign subsidiaries: Evidence from the Korean market. Organizations and Markets in Emerging Economies 9: 123-34. [CrossRef] 
Paruchuri, Srikanth, and Snehal Awate. 2017. Organizational knowledge networks and local search: The role of intra-organizational inventor networks. Strategic Management Journal 38: 657-75. [CrossRef]

Podolny, Joel M., and James N. Baron. 1997. Resources and relationships: Social networks and mobility in the workplace. American Sociological Review, 673-93. [CrossRef]

Podolny, Joel M., and Karen L. Page. 1998. Network forms of organization. Annual Review of Sociology 24: 57-76. [CrossRef]

Portes, Alejandro, and Julia Sensenbrenner. 1993. Embeddedness and immigration: Notes on the social determinants of economic action. American Journal of Sociology 98: 1320-50. [CrossRef]

Provan, Keith G., and Patrick Kenis. 2008. Modes of network governance: Structure, management, and effectiveness. Journal of Public Administration Research and Theory 18: 229-52. [CrossRef]

Reagans, Ray, and Bill McEvily. 2003. Network structure and knowledge transfer: The effects of cohesion and range. Administrative Science Quarterly 48: 240-67. [CrossRef]

Rogers, Everett M. 1995. Diffusion of Innovations, 4th ed. New York: Free Press.

Sandefur, Rebecca L., Edward O. Laumann, and John P. Heinz. 1999. The changing value of social capital in an expanding social system: Lawyers in the Chicago Bar, 1975 and 1995. In Corporate Social Capital and Liability. Edited by Roger Th A. J. Leenders and Shaul M. Gabbay. Norwell: Kluwer Academic Publishers, pp. 217-33.

Shipilov, Andrew V. 2006. Network strategies and performance of Canadian investment banks. Academy of Management Journal 49: 590-604. [CrossRef]

Szulanski, Gabriel. 1996. Exploring internal stickiness: Impediments to the transfer of best practice within the firm. Strategic Management Journal 17: 27-43. [CrossRef]

Tortoriello, Marco. 2015. The social underpinnings of absorptive capacity: The moderating effects of structural holes on innovation generation based on external knowledge. Strategic Management Journal 36: 586-97. [CrossRef]

Tsai, Wenpin. 2001. Knowledge transfer in intraorganizational networks: Effects of network position and absorptive capacity on business unit innovation and performance. Academy of Management Journal 44: 996-1004. [CrossRef]

Tsai, Wenpin. 2002. Social structure of "coopetition" within a multiunit organization: Coordination, competition, and intraorganizational knowledge sharing. Organization Science 13: 179-90. [CrossRef]

Tsai, Wenpin, and Sumantra Ghoshal. 1998. Social capital and value creation: The role of intrafirm networks. Academy of Management Journal 41: 464-76. [CrossRef]

Umphress, Elizabeth Eve, Giuseppe (Joe) Labianca, Daniel J. Brass, Edward (Eli) Kass, and Lotte Scholten. 2003. The role of instrumental and expressive social ties in employees' perceptions of organizational justice. Organization Science 14: 738-53. [CrossRef]

Uzzi, Brian. 1997. Social structure and competition in interfirm networks: The paradox of embeddedness. Administrative Science Quarterly 42: 35-67. [CrossRef]

Uzzi, Brian, and Ryon Lancaster. 2003. Relational embeddedness and learning: The case of bank loan managers and their clients. Management Science 49: 383-99. [CrossRef]

West, Stephen G., Leona S. Aiken, and Jennifer L. Krull. 1996. Experimental personality designs: Analyzing categorical by continuous variable interactions. Journal of Personality 64: 1-48. [CrossRef]

Yoon, Woojin, and Sangwook Han. 2017. Does the potential for developing new technology lead to successful technology transfer commercialisation? The case of public R\&D outputs in Korea. International Journal of Management Practice 10: 93-108. [CrossRef]

Yoon, Woojin, and Eunjung Hyun. 2010. Economic, Social and institutional conditions of network governance. Management Decision 48: 1212-29. [CrossRef]

Yoon, Woojin, Diane Y. Lee, and Jaeyong Song. 2015. Alliance network size, partner diversity, and knowledge creation in small biotech firms. Journal of Management and Organization 21: 614-26. [CrossRef]

Yoon, Woojin, Sang Ji Kim, and Jaeyong Song. 2016. Top management team characteristics and organizational creativity. Review of Managerial Science 10: 757-79. [CrossRef] 